Renata Mercês Oliveira de Faria ${ }^{1}$

Jane Dutra Sayd ${ }^{2}$

\title{
Abordagem sócio-histórica sobre a evolução da assistência ao parto num município de médio porte de Minas Gerais (1960-2001)
}

\author{
A socio-historical approach to the evolution of childbirth \\ assistance in a medium-sized city in Minas Gerais (1960-2001)
}

Universidade Federal de uiz de Fora. Campus Universitário, Bairro São Pedro. 36.036-900 Juiz de Fora MG.

renata.faria@ufff.edu.br ${ }^{2}$ Instituto de Medicina Social, Universidade do Estado do Rio de Janeiro.

\begin{abstract}
The historical sequence of the evolution of the choice of birth delivery (normal, cesarean section, and forceps) between 1960 and 2001 was evaluated using data from the three oldest maternity hospitals affiliated to the Brazilian Unified Health System (SUS) in the city of Juiz de Fora, Brazil. The so-called serial history method enables comparisons of historical events over a given time period. Greater incorporation of technology and an increase in cesarean sections were detected prior to 1998, when administrative ruling No. 2816 was proposed by the Ministry of Health, which reversed the trend back to normal birth deliveries. The form of delivery was also associated with the admission category, which points to a decidedly political discussion about social inequalities that are interrelated with diverse variables including gender and social class. Understanding inequalities and discussing their more difficult ramifications, with respect to morbidity, mortality, and unequal standards of care, are preconditions to finding solutions to these ubiquitous problems.
\end{abstract}

Key words Childbirth, Medical assistance, History of medicine
Resumo Trata-se de caracterizar a evolução da série histórica quanto ao tipo de parto, normal, cesárea e fórceps, no período de 1960 a 2001, nas três maternidades mais antigas e conveniadas ao Sistema Único de Saúde (SUS) de Juiz de Fora. O método utilizado denomina-se história serial e permite a comparabilidade entre eventos históricos em determinado período de tempo. Foi identificado o aumento de incorporação tecnológica nesta trajetória e o crescente uso da cesariana até 1998, quando se identifica o impacto da portaria $n^{\circ} 2816$, proposta pelo Ministério da Saúde, através de inversão dessa tendência com elevação do número de partos normais. A diferenciação constatada do tipo de parto de acordo com a categoria de internação aponta para uma discussão marcadamente politi$\mathrm{ca}$, que diz respeito às relações sociais em que se entrelaçam desigualdades de diversas ordens, entre elas as de gênero e de classe social. Conhecer as desigualdades e problematizar sua existência, traduzida em perfis de morbimortalidade e padrões desiguais de assistência, é precondição para obter o encaminhamento da solução.

Palavras-chave Parto, Assistência médica, História da medicina 


\section{Introdução}

O presente artigo retrata a evolução da assistência ao parto sob a perspectiva sócio-histórica, no período de 1960 a 2001, através da identificação do número de partos normais, cesarianas e fórceps. Este recorte cronológico foi possível ser realizado em Juiz de Fora (MG), devido à existência de arquivos disponíveis nas maternidades estudadas e por demarcar um momento de grandes avanços científicos e tecnológicos, em especial: os antibióticos, a transfusão sanguínea e as técnicas cirúrgicas. O período final foi estabelecido pelo fato de englobar a política implantada pelo Ministério da Saúde, através de um conjunto de ações por meio de portarias ministeriais que, em seu conjunto, constituiu o Programa de Humanização no Pré-natal e Nascimento ${ }^{1}$. Este período assistiu a uma mudança de comportamento tanto entre médicos como entre parturientes no Brasil: o surgimento da adoção da cesariana como principal técnica de parto.

Em Juiz de Fora os indicadores estatísticos não divergem da situação nacional, com um índice médio de cesarianas de $51 \%$, em $2001^{2}$. Cidade situada na Zona da Mata, a sudeste do Estado de Minas Gerais (MG), é considerada polo regional devido à sua infraestrutura de comércio e serviços. Possui uma universidade federal e uma rede de serviços de saúde que atende usuários de várias cidades do seu entorno. Apresenta uma população de 516.247 habitantes, de acordo com dados censitários de $2010^{3}$.

$\mathrm{O}$ alto índice de cesarianas em Juiz de Fora denota um modelo de atenção ao parto altamente intervencionista. Nas maternidades particulares, sem convênio com o SUS, o índice de partos operatórios ultrapassava os $90 \%{ }^{2}$. Cabe ressaltar que a Organização Mundial da Saúde recomenda, como parâmetro aceitável, um percentual em torno de $15 \%{ }^{4}$.

A razão média de mortalidade materna em Juiz de Fora, no período de 1996 a 2002, é de 97 por 100.000 nascidos vivos ${ }^{2}$. O Ministério da Saúde admite que uma razão de mortalidade materna superior a 20 óbitos maternos por 100.000 nascidos vivos é muito elevada ${ }^{5}$.

Este retrato da assistência impulsionou a busca pela compreensão desses dados. O caminho escolhido foi o de conhecer o processo histórico e diferentes contextos sociais e políticos que influenciaram os índices emergentes em cada momento histórico, muitas vezes vistos como algo natural, próprio da evolução científica.

O primeiro contato com os registros históricos sobre a assistência ao parto foi em uma das maternidades mais antigas de Juiz de Fora. A motivação para investigar os aspectos dessa mudança foi ampliada pelo encontro, nesta maternidade, de um setor de arquivos bem cuidado e valorizado. Os registros dos tipos de parto eram compilados anualmente, com apresentação do cálculo dos índices de mortalidade perinatal e materna. Manuscritos em caligrafia caprichada compreendem partos "normais" e "anormais", com registros para cirurgias e uso de fórceps, registrados como médio ou baixo. Os casos de morte materna apresentam relatos onde são identificadas as causas dos óbitos. Encontrou-se também a divisão da clientela de acordo com a forma de pagamento pela internação que, no começo da década de 60, era classificada em enfermaria geral e classes particulares.

Com base nesses arquivos decidiu-se realizar um estudo do tipo história serial para acompanhar essa evolução e procurar, nos contextos mutantes ao longo do tempo, pistas para a conformação da curva ascendente de partos por técnica cesariana. Foi possível encontrar registros em mais duas outras maternidades, com menos especificações e algumas falhas, mas que permitiram acompanhar a evolução de alguns fenômenos.

O presente trabalho retrata, portanto, um panorama histórico da assistência ao parto (1960-2001), em nível local, mas que possibilita reflexões importantes acerca da racionalidade médica de cada momento histórico, para além da neutralidade científica, amparada no bem-estar da mãe e do bebê.

Padrão de assistência ao parto no Brasil no período estudado (1960-2001)

O modelo de assistência ao parto no Brasil foi altamente influenciado pelo paradigma americano, que se caracteriza pela institucionalização, utilização de novas tecnologias, incorporação de grande número de intervenções, preocupação maior com patologias e a assistência condicionada à conveniência do profissional.

No Brasil da década de 60, com a criação do Instituto Nacional de Previdência Social (INPS), ocorre um forte impulso com relação à incorporação de tecnologia médica, apoiada pela intervenção estatal. Essa tendência gerou um estímulo à privatização descontrolada da assistência à saúde, sendo também uma forte fonte de corrupção.

Em 1979, as hospitalizações desnecessárias financiadas pela previdência social atingiram 30\% a $40 \%$, segundo estimativas dos dados da Dataprev. As cesarianas comprovadamente desneces- 
sárias e financiadas pelo Inamps (Instituto Nacional de Assistência Médica da Previdência Social) chegaram a cento e oitenta e seis mil $(186.000)^{6}$.

Um estudo sobre o aumento da incidência de cesariana, no final da década de 60, apontou para uma correlação existente entre esse acréscimo e a forma de pagamento ao parto na rede contratada com pagamento por unidade de serviço. O autor descreve que em um hospital de Brasília, onde o sistema de pagamento era individual por unidade de serviço, a taxa de cesárea, em pacientes do INPS, era de quase $50 \%$, sendo 10 vezes menor a incidência no caso de gestantes "indigentes”. Essas diferentes taxas de cesárea foram verificadas ainda em outras quatro instituições estudadas. Diante de tais dados, o autor propôs uma reflexão sobre essa situação, desvinculando o aumento do número de cesarianas do progresso científico exclusivamente. Aponta o pesquisador para a existência de todo um contorno social no uso da tecnologia médica ${ }^{7}$.

Outros autores ${ }^{8-9}$ corroboram os dados encontrados referentes à diferenciação da incidência de cesáreas entre classes sociais e/ou sistemas de financiamento da assistência ao parto, tornando-se evidente nestes estudos que a assistência médica, na sociedade capitalista, restabelece a desigualdade social dos corpos através da medicina de classes.

Na década de 90, o Brasil viveu o auge do processo de cirurgificação, sendo eleito o país com maior taxa de cesárea do mundo. Esse recorde, nada invejável, provocou uma série de iniciativas por parte do Ministério da Saúde, tais como a elaboração de portarias referentes ao Programa de Humanização no Pré-Natal e Nascimento'. Uma das medidas refere-se à imposição de limites para o pagamento de cesarianas pelo SUS, estabelecendo percentuais máximos por ano, de modo a atingir ao final de um período de dois anos a meta de no máximo $30 \%$ de partos operatórios ${ }^{10-11}$. Outras portarias propostas pelo Ministério, no sentido de mudar o modelo de assistência ao parto no Brasil, foram: o apoio à realização de cursos de Enfermagem Obstétri$\mathrm{ca}^{12} \mathrm{e} \mathrm{o}$ apoio à construção de Centros de Parto Normal no país ${ }^{13}$.

Essas medidas resultam do movimento de redefinição das relações humanas na assistência ao parto, na perspectiva dos direitos humanos que foi denominado no Brasil como humanização do parto ${ }^{14}$. Humanização, inclusive, orientada pelo conceito de tecnologia apropriada e de respeito à fisiologia de acordo com as evidências científicas sobre efetividade e segurança, em opo- sição à prática orientada pela opinião e tradição ${ }^{4}$. A incorporação da humanização tornou-se constante na elaboração das políticas de assistência ao parto, pelo Ministério da Saúde.

\section{Construção das séries históricas}

Em primeiro lugar faz-se necessário destacar a dificuldade encontrada diante do desejo de realizar um estudo histórico quanto à evolução da assistência ao parto em Juiz de Fora. No município, no âmbito da Secretaria Municipal de Saúde, os dados existentes sobre essa temática datam a partir de 1994, com a implantação do Sistema de Nascidos Vivos (Sinasc). No Brasil, a via de parto, salvo experiências pontuais, não fazia parte do sistema regular de informações vitais de saúde. Até os anos 70, dispõe-se apenas de informações parciais e geralmente referentes a instituições isoladas. A partir de então é que se começou a avaliar os dados nacionais do antigo Instituto Nacional de Previdência Social (INPS) com relação aos partos financiados pela entidade e que representavam cobertura aproximada de $70-75 \%$ de todos os nascimentos do país. Esse foi o trabalho isolado e pioneiro do Professor Carlos Gentile de Mello, no Rio de Janeiro, que, juntamente com os dados coletados pelo IBGE, serviu de base para a avaliação da situação brasileira das cesarianas em meados da década de 80 (oitenta) ${ }^{15}$.

As três maternidades estudadas foram escolhidas por serem conveniadas ao SUS e responsáveis por 5.584 dos 7042 nascimentos vivos de mães residentes em Juiz de Fora no ano de 2001 representando, portanto, $79,3 \%$ do total desses nascimentos no município ${ }^{2}$. Além de serem as mais antigas da cidade.

O primeiro contato com os registros históricos sobre a assistência ao parto em Juiz de Fora aconteceu através da ida à Maternidade I, que realiza um grande número de partos em Juiz de Fora (quase 40\%). O acesso à seção de arquivos dessa maternidade foi surpreendente pela organização dos dados históricos apresentados, anualmente, desde sua fundação em 1926. Já nas outras duas (Maternidades II e III) existem registros do tipo de parto em cadernos que tiveram que ser localizados em meio a outros documentos, sendo que o quantitativo de partos não era contabilizado anualmente, portanto, a montagem das frequências anuais dos eventos em estudo foi realizada pela pesquisadora. Aconteceram períodos falhos ao longo da série devido a não localização de alguns cadernos específicos para anotações dos partos, como será apontado nos gráficos. 
Tendo como eixo principal da pesquisa as modalidades de parto, a coleta dos dados nas maternidades foi guiada pela identificação das mesmas, quais sejam: normal, cesárea e fórceps.

O trabalho empírico foi norteado pelo que se denomina história serial. Este método histórico foi importado do processo da curva econômica para diferentes disciplinas, pois se tornou evidente e necessária a possibilidade de traçar curvas de acontecimentos repetitivos em economia, em demografia, incluindo mesmo certos domínios da cultura ou da política. Uma das grandes transformações ocorridas na elaboração do fato histórico foi a constituição do evento histórico em séries e em unidades repetitivas por determinados períodos de tempo ${ }^{16}$. Em uma história cujos dados estão constituídos em séries, o evento já não se define por uma etapa na marcha para um fim, mas para a sua comparabilidade com outro fato que o preceda ou que o siga.

A história serial é aquela que codifica, que anexa o aberrante ao significativo, é uma história ligada ao presente, uma história útil, fornecedora de índices, uma história que vai buscar suas problemáticas nas ciências do homem do presente, adaptando-as às estruturas do passado ${ }^{17}$.

Com base nos arquivos destas três casas de saúde, realizou-se um estudo do tipo história serial por possibilitar o acompanhamento da evolução da assistência ao parto e procurar, nos contextos mutantes ao longo do tempo, pistas para a conformação da curva ascendente daqueles por técnica cesariana, e, simultaneamente, avaliar suas variações ao lado de modificações nas formas de financiamento à assistência ou no discurso técnico-científico da medicina.

Uma série histórica propicia reflexões, aponta tendências, ajuda a formular hipóteses e pode confirmar associações.

\section{Maternidade I:}

uma história em destaque (1955-2001)

Os dados referentes à Maternidade I possibilitaram um estudo mais abrangente da série histórica através da comparação dos índices de tipo de parto e as formas de financiamento público por convênio e pagamento privado. A construção da série histórica desta maternidade foi iniciada em 1955, um quinquênio anterior com relação às outras duas maternidades. Os dados foram agrupados de cinco em cinco anos, a fim de facilitar a construção das séries históricas.

O Gráfico 1 apresenta uma comparação entre a incidência de cesarianas e fórceps de acordo com a categoria de internação (fonte de financi-

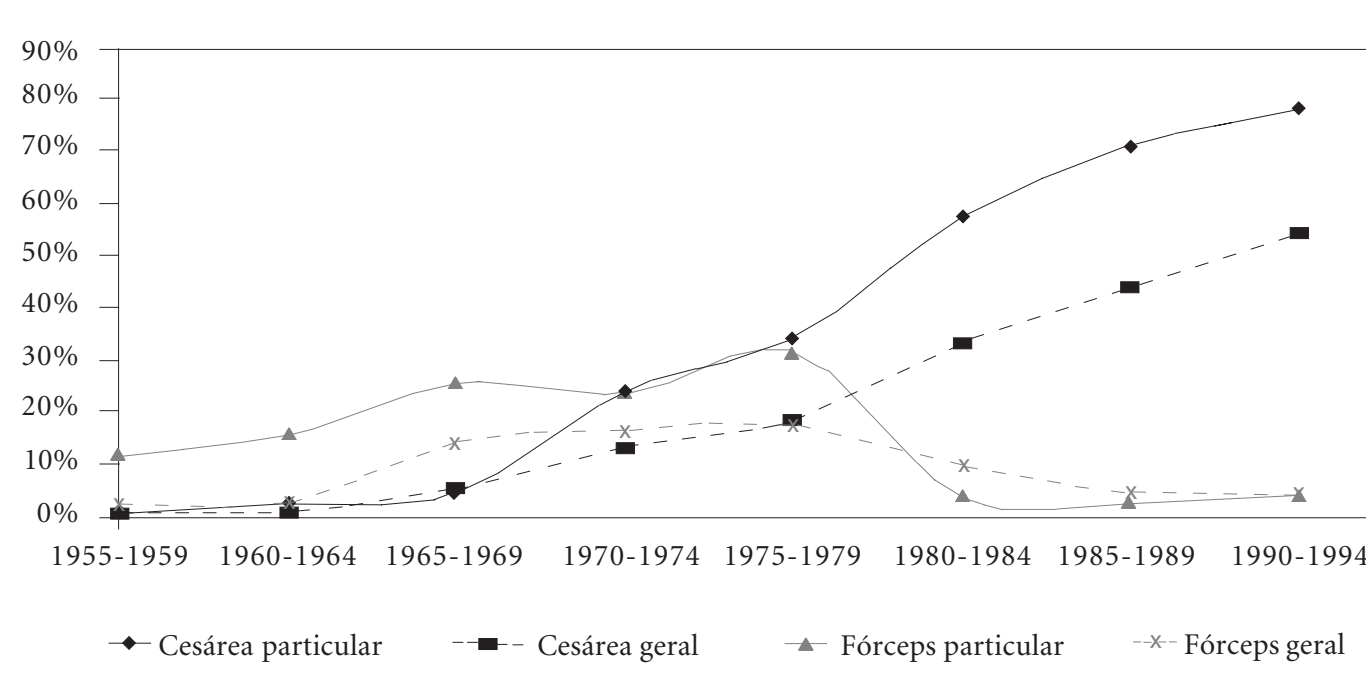

Gráfico 1. Evolução comparativa da proporção de cesarianas e fórceps entre o atendimento particular e o geral na Maternidade I (1955-2001)

Fonte: Arquivo da Maternidade I

Notas: Em 1982, sem dados do tipo de parto por categoria de internação; Em 1989, sem dados do tipo de parto por categoria de internação; Sem nenhum dado referente ao ano de 1990; A partir de 1995, dados inexistentes sobre uso de fórceps nesta Maternidade 
amento), quais sejam: particular ou geral. Por particular entende-se pagamento direto do paciente ao estabelecimento hospitalar; o que foi classificado como categoria geral, neste processo evolutivo, foi se modificando historicamente, como será exposto na análise do gráfico.

No período de 1955 a 1967 a divisão da clientela se dava através das denominações particular e geral. A classificação dos partos dava-se entre normais e anormais, com maior incidência dos anormais na classe particular: em 1958, na enfermaria geral, num universo de 611 mulheres, ocorreram 4 fórceps médios e 15 baixos. Já na classe particular, num total de 529 mulheres, foram realizados 20 fórceps médio e 36 fórceps baixo. Essa diferenciação acontece também para a vácuo-extração: no ano de 1961, aconteceram seis dessas intervenções ( 4 baixas, 1 média e 1 alta) na enfermaria geral contra 72 (34 baixas, 35 médias e 3 altas) na classe particular.

Constata-se ainda que no período de 1955 até 1965 a incidência de cesarianas no atendimento particular é um pouco mais elevada do que na enfermaria geral, mas ainda estão muito próximas. No caso do fórceps, porém, a incidência é bem maior na categoria particular. Essa diferença se mantém até 1979 , com o declínio de sua indicação, tendo a partir de então maior ocorrência na categoria geral.

A grande incidência de fórceps na categoria particular de 1965 a 1979, principalmente no período de 1975-79 quando atingiu 32\% do total de partos, denota uma grande idealização desta intervenção na época, quase um virtuosismo, aplicado à classe que podia pagar. A valorização do fórceps como modelo de intervenção ${ }^{18-20}$ é reforçada na assertiva de que [...] no que diz respeito ao uso do fórceps, esta é a mais comum das operações obstétricas ${ }^{18}$. Aponta ainda que a incidência da operação é crescente, avizinhando-se, em maternidades americanas, a 100\% nas primiparturientes. No ano de 1984, porém, surge outra situação: a da diminuição do fórceps, tendo em vista a segurança da cesariana ${ }^{19}$. O movimento de diminuição do fórceps e aumento da cesariana pode ser verificado no gráfico no período 1980-1984.

Os registros referentes à década de 60 apresentam descrições das indicações pelas quais as cesarianas foram realizadas. Já nessa década, existe uma diferença entre os índices de cesáreas realizadas na enfermaria geral e o realizado nas classes particulares. É no período de 1970-74 que ocorre uma elevação no número de cesarianas em ambas as categorias: particular e geral. Acontece também o aumento da diferença na incidên- cia entre as duas categorias, sendo maior na particular. Cabe apontar que nesse período, com a criação do Instituto Nacional de Previdência Social, acabaram as diferenças entre os institutos de pensão até então existentes e ampliou- se o acesso aos cuidados médicos e serviços de saúde da população inserida no mercado de trabalho, surge uma nova categoria de internação: a dos previdenciários. Portanto, o processo de medicalização e hospitalização encontrou uma forte via institucionalizada, possibilitando a popularização de seus conhecimentos e "avanços" e, por consequência, "normalizando" a vida, o processo saúde-doença dos indivíduos, no caso específico dos trabalhadores e suas famílias.

Nos registros desse momento específico, observa-se que, juntamente com a inserção da clientela via INPS, novas intervenções aparecem, sendo descritas com muito detalhamento, como, por exemplo, as episiotomias realizadas (374 num total de 782 partos normais), as cesáreas iterativas (18), aceleração do parto com ocitócico (295), indução (28).

Começa a surgir também o uso de anestesias: geral (454), local (229), pudenda (10) e raque (1). Em 1970, aparece na descrição a anestesia peridural (380), narcose ou geral (643) e raque (154). Em 1974, a peridural passa a ser predominante.

Na década de 70, nos registros da Maternidade I, a categoria geral muda sua denominação para indigentes. Para a realização da tabela foram somadas as categorias de indigentes e previdenciários com o objetivo de comparar com a particular. Porém, verificou-se uma diferenciação das intervenções entre a categoria de indigentes e a de previdenciários, sendo maior na última. Para melhor visualização dessa situação, podemos citar que, no ano de 1977, a incidência de fórceps médio foi de $27,4 \%$ na categoria particular, 5,6\% na de previdenciários e 3\% na de indigentes. Essa intervenção diferenciada entre as categorias particular, previdenciária e indigente foi verificada também em estudos nacionais ${ }^{7-9}$.

A partir de 1979, a descrição das categorias muda novamente, sendo a seguinte: geral (que reaparece no lugar de indigentes), particular e duas novas categorias - Inamps e Funrural. Ainda nesse ano, os dados da Maternidade foram informatizados e percebe-se que, apesar das facilidades que a informática possibilita, ao longo do tempo houve uma piora na qualidade dos registros: cada vez mais os registros apresentam dados já agregados, dificultando análises mais detalhadas.

Em 1986 não aparece mais nos registros da Maternidade a categoria Funrural, e em 1987, as 
categorias de internação passam a ser novamente previdenciários, indigentes e particulares. Cabe ressaltar que, em 1987, não se vê mais nos registros do tipo de parto a classificação parto pélvico. Este fato deixa uma interrogação se esses partos ainda eram realizados, mas não registrados, ou se, de acordo com a literatura de referência obstétrica, nessa situação tem-se indicado a realização da cesariana ${ }^{19}$.

A categoria indigentes reaparece no ano de 1988, o que contraria os preceitos de universalização e visão da saúde como direito de todos e dever do Estado, defendida e aprovada pela Constituição neste mesmo ano. Tal fato aponta para o processo de transição vivido pela área da saúde no final da década de 80 e início da década de 90 , quando começa a ser viabilizada a proposta do Sistema Único de Saúde no Brasil. No período de 1991 a 1994 a categorização volta a ser geral, particular e Inamps, tendo este sido extinto em 1990 e transformado em Secretaria de Assistência à Saúde, com a obrigação de promover atendimento a toda população, independentemente do vínculo contributivo. A designação SUS aparece so- mente em 1995, além das categorias particulares e convênios.

A série específica referente à Maternidade I termina neste período, sendo que os dados de 1994 a 2001 serão visualizados na série histórica das três maternidades estudadas, a fim de propiciar um olhar da evolução da assistência ao parto como um todo.

\section{Série histórica do tipo de parto em Juiz de Fora (1960-2001)}

A evolução do tipo de parto (normal, cesárea e fórceps) em Juiz de Fora, no período de 1960 a 2001, nas três maternidades deste estudo, está apresentada a seguir, no Gráfico 2.

A curva histórica em Juiz de Fora apresenta no início da década de 60 os percentuais de parto normal e de cesariana muito distantes, sendo a porcentagem do primeiro de $90 \%$ e da segunda aproximadamente $4 \%$, vencida pela de fórceps, em torno de $6 \%$. A partir de então, começa a haver uma queda no número de partos normais e um aumento no número de cesarianas. O núme-

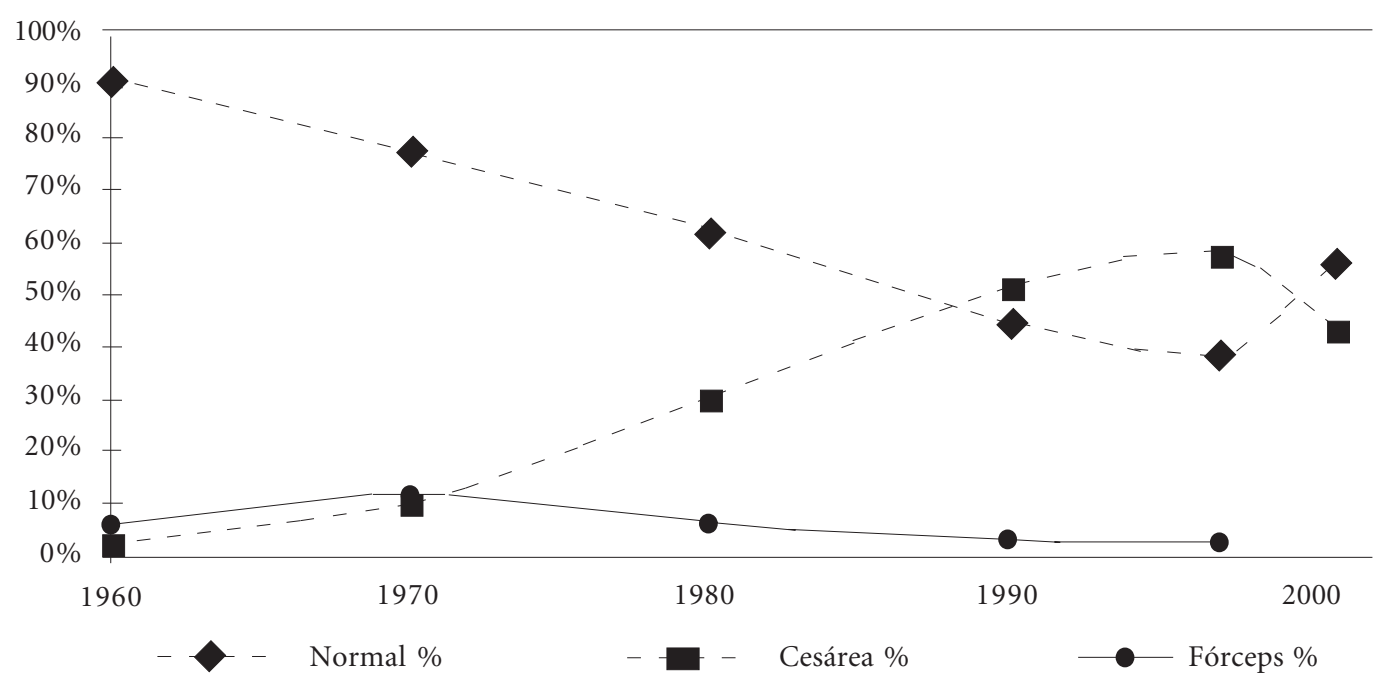

Gráfico 2. Evolução Histórica do Tipo de Parto em Juiz de Fora (1960 a 2001)

Notas: Os dados do ano de 1960 referem-se ao período de fevereiro a dezembro; Dados referentes ao período de 01/09/1961 a 24/ 05/1962; Sem dados referentes à década de 1970, somente o ano de 1979; Dados de 1981, pois em 1980 não há registro do número de partos normais e fórceps. Para isto, observou-se que os dados absolutos eram semelhantes aos anos próximos: 1979 1983; Dados de 1991, pois em 1990 não há dados referentes a fórceps; A partir de 2000, ocorreu uma mudança na Declaração de Nascido Vivo, desaparecendo a categoria fórceps como tipo de parto.

Fonte: Arquivo da Maternidade I; Arquivo da Maternidade II; Arquivo da Maternidade III; Sistema de Nascidos Vivos/Secretaria Municipal de Saúde de Juiz de Fora 
ro de fórceps é ascendente até 1970, quando atinge o seu pico e depois apresenta queda constante. O fórceps até este período era mais realizado do que a cesariana, tendo em vista que é somente ao longo da década de 60 que tal intervenção tornase mais segura, com os progressos que se seguiram nas técnicas cirúrgicas, anestesia, hemoterapia, antibioticoterapia, controle da contaminação cirúrgica e em outras áreas correlatas ${ }^{15}$.

O movimento de queda do índice de parto normal e o aumento da cesárea fizeram com que ocorresse o encontro desses dados ao final da década de 80 , mais precisamente em 1988. A partir disso, a incidência de cesárea passa a ser maior do que a de parto normal.

Em 1997, o índice de partos operatórios em Juiz de Fora alcança o seu maior valor, de $63,3 \%{ }^{2}$, sendo que nos anos subsequentes observa-se uma tendência de elevação dos partos normais. Essa inversão está correlacionada com a medida tomada pelo Ministério da Saúde, diante do crescente índice de cesarianas no Brasil. A portaria n. $2816^{10}$ determina controle crítico sobre o pagamento máximo de cesarianas em relação ao total de partos financiados pelo SUS, por hospital, sendo que se os limites propostos fossem ultrapassados não ocorreria o pagamento pela realização das mesmas.

No ano de 2000, houve uma mudança na Declaração de Nascido Vivo, instrumento de coleta de dados do Sinasc, não existindo mais a categoria fórceps no campo Tipo de Parto, o que inviabiliza a análise da utilização dessa intervenção a partir desta data. Verifica-se, portanto, que a Maternidade I apresenta uma incidência maior no uso de fórceps, se comparada com as outras duas maternidades, dando-lhe uma identidade específica em termos da assistência ao parto em Juiz de Fora. De acordo, com dados do Sinasc referentes ao uso de fórceps nesta Maternidade, nota-se influência da portaria n. $2.816^{10}$ através do aumento do uso deste de 2,2\% no período de 1995 a 1997, para 4,5\% em 1998. A valorização dessas duas intervenções, cesárea e fórceps, fica evidente, pois quando não se pode realizar a primeira, recorre-se a outra, talvez pelo conhecimento e habilidade adquiridos ao longo do processo histórico, como pode ser verificado.

\section{Discussão}

O presente estudo possibilitou um panorama histórico da assistência ao parto em Juiz de Fora no período de 1960 a 2001, que por sua vez propicia reflexões transcendentes pela qualidade de desmistificar a racionalidade médica emergente de cada momento, trazendo à tona suas intenções e realizações, para além da neutralidade científica.

A diferenciação constatada do tipo de parto de acordo com a categoria de internação identificadas neste estudo como - geral e particular aponta para uma discussão marcadamente política, que diz respeito às relações sociais em que se entrelaçam desigualdades de diversas ordens, entre elas as de gênero e de classe social. Os profissionais envolvidos na assistência ao parto têm que equacionar o manejo técnico dessa contradição: para as mulheres atendidas pelo SUS, maior número de partos normais e para as mulheres atendidas em serviços da rede privada, um altíssimo índice de cesarianas. No momento em que o fórceps era valorizado pela classe obstétrica, na década de 70, tinha uma alta incidência na categoria particular, sendo menor na geral. Como apontam alguns autores ${ }^{21}$, conhecer as desigualdades e problematizar sua existência, traduzida em perfis de morbimortalidade e padrões desiguais de assistência é precondição para obter o encaminhamento da solução.

A lógica de produtividade na assistência ao parto especificamente no caso de Juiz de Fora é bastante prejudicial, nas três maternidades do estudo (que realizam em torno de $80 \%$ dos partos) os profissionais envolvidos com a assistência ao parto não possuem vínculo salarial com as instituições, recebendo, portanto, por procedimentos realizados em esquema de plantão.

É sabido que o acompanhamento do trabalho de parto demanda, na maioria das vezes, muito mais horas do que a realização de uma cesariana. Outro fator importante é que essas três maternidades, ainda que formalmente integradas à rede pública através de contratos e convênios, são administradas e conduzidas pelo setor privado. A visão do trabalho de parto e do parto como eventos de risco, além da necessidade de conformá-los ao processo de produção do hospital implicam, quase sempre, na tentativa de regulação e controle do parto pelos médicos, levando a inevitáveis interferências ${ }^{22}$. É nesse sentido que se propõe a atuação dos enfermeiros obstetras ${ }^{12}$, pois que, decorrente de sua formação e atuação, estes profissionais enfatizam mais os aspectos fisiológicos, emocionais e socioculturais do processo produtivo. Não é a forma de remuneração da assistência ao parto, isoladamente, que interfere no índice de cesáreas, mas sim uma série de variáveis que podem influenciar no tipo de contrato que se estabelece entre a paciente e o profissional ${ }^{23}$. 
A portaria n. 2.816, no ano de $1998^{10}$, veio impor limites aos abusos existentes no caso da realização de cesarianas, pelo menos para os partos realizados pelo SUS. Essa portaria, como se verificou na curva histórica, teve impacto no município de Juiz de Fora com a queda verificada do percentual de cesarianas. A lógica do financiamento, o papel do poder econômico e corporativo na definição das políticas, portanto, aparece mais uma vez, demonstrando a existência de diversos fatores extratécnicos e extrabiológicos nas condutas profissionais e institucionais.

Outra consideração importante relaciona-se com a alta incidência de cesarianas na clientela particular (pagamento direto do paciente ao médico e estabelecimento hospitalar) e de medicina de grupo (cooperativas, convênios ou empresas médicas) dos hospitais: em torno de $90 \%$ em $2001^{2}$. O sistema de saúde suplementar do país tem crescido, hoje são 47 milhões de brasileiros com plano de saúde, e ostenta a maior prevalência de cesarianas do mundo ${ }^{24}$. A interface entre o SUS e a saúde suplementar gera conflitos e contradições que devem ser levadas em consideração quando se pensa em melhorar os desfechos de saúde e o modelo de assistência como um todo.

Evidencia-se a necessidade da continuidade na investigação dos fatores que promovem o aumento de partos cesarianos no Brasil, uma vez que podem ocasionar uma série de complicações tanto para as mães quanto para seus filhos. Além disso, os índices encontram-se muito acima do recomendado pela OMS, demonstrando que políticas públicas dirigidas à redução das taxas de cesarianas no país são urgentes e necessárias ${ }^{25}$.

Em Juiz de Fora, no ano de 2011, o índice de cesariana foi de $63 \%{ }^{26}$. Verifica-se, portanto, que as medidas das Portarias referentes à limitação da realização de cesarianas não se sustentaram ao trazer mudanças momentâneas, estimuladas por uma política de assistência ao parto guiada principalmente pelo viés financeiro, sendo urgente um trabalho contínuo e interdisciplinar, onde diversos aspectos dessa assistência sejam valorizados.

Talvez esse seja um dos grandes desafios do Ministério da Saúde: reverter a mentalidade dos recursos humanos envolvidos, sendo essencial uma aliança intersetorial com o Ministério da Educação, com propostas de mudanças na formação dos profissionais de saúde para a superação do modelo da "fisiologia patológica".

Através da trajetória histórica apresentada, percebe-se que o evento estudado - tipo de parto - é bastante sensível a injunções políticas, seus respectivos financiamentos e a variáveis que expressam classe econômica ${ }^{23}$. Perante as iniquidades encontradas no período estudado, uma grande repercussão positiva foi a mobilização social na busca pela humanização. A adoção de uma lógica de atenção centrada na qualidade das relações humanas, na satisfação e na responsividade de usuários e profissionais, no uso racional e compartilhado das tecnologias e na abertura de espaços para um verdadeiro exercício dos direitos ${ }^{27}$. Embora o desdobramento das práticas de saúde dos programas elaborados pelo Ministério da Saúde ganhe sentidos diversos, nota-se que a proposta da humanização está consolidada como um norte a ser seguido e implantado, inclusive na atual estratégia denominada Rede Cegonha ${ }^{28}$.

E, para a construção do processo de humanização, profissionais e instituições, devem urgentemente desenvolver tecnologia voltada ao fortalecimento das pessoas para o exercício de seus direitos, incluindo a abordagem de questões como a informação sobre gravidez, parto e procedimentos médicos, a negociação com profissionais e serviços, os grupos de autoajuda, o envolvimento dos pais e familiares, incorporando esses fatores desde o pré-natal. Enfim, tornase necessário ainda o deslocamento da discussão meramente técnica para a da negociação de necessidades e direitos dos sujeitos humanos envolvidos na cena do parto.

Propõe-se enfim que no campo da saúde reprodutiva, a questão da iatrogenia biológica e social que o poder indiscriminado da medicina exerce sobre corpos e mentes de mulheres e homens deva ser encarada para além da prevenção aos agravos da saúde; que seja considerada a necessidade de uma vigilância epistemológica ${ }^{29}$, que inscreva no campo da ética, e mesmo da moral, os modos de andar da "ciência moderna" nessa área de conhecimento e prática. 


\section{Colaboradores}

RMO Faria elaborou o artigo a partir de sua dissertação de mestrado, e JD Sayd foi orientadora da referida dissertação, contribuiu na concepção e revisão final do artigo.

\section{Referências}

1. Brasil. Ministério da Saúde (MS). Programa de humanização no pré-natal e nascimento: informações para gestores e técnicos. Brasília: MS; 2000.

2. Costa TJNM. Relatório do sistema de nascidos vivos em Juiz de Fora/MG em 2001. Juiz de Fora: Departamento de Epidemiologia,Secretaria Municipal de Saúde de Juiz de Fora; 2002.

3. Instituto Brasileiro de Geografia e Estatística (IBGE). Censo demográfico 2010. [página na Internet]. [acessado 2012 jun. 21]. Disponível em: http://www. ibge. gov.br/cidadesat/link.php? codmun $=313670$.

4. Organização Mundial de Saúde (OMS). Maternidade segura. Assistência ao parto normal: um guia prático. Genebra: OMS; 1996.

5. Brasil. Ministério da Saúde (MS). Portaria MS/GM $n^{\circ} 723$ de 10 de maio de 2001. Aprova, na forma dos anexos I, II e III desta portaria, a relação de indicadores a serem pactuados no ano 2001 pelos estados e municípios. Diário Oficial da União 2001; 14 maio.

6. Fundação Oswaldo Cruz (Fiocruz). A acumulação capitalista e a crise do modelo do setor saúde. Rio de Janeiro: Fiocruz; 1995.

7. Mello CG. A epidemiologia da cesárea. In: Mello CG, organizador. Saúde e assistência médica no Brasil. São Paulo: Cebes-Hucitec; 1977. p. 121-129.

8. Gentile FP, Noronha Filho G, Cunha AA. Associação entre a remuneração da assistência ao parto e a prevalência de cesariana em maternidades do Rio de Janeiro: uma revisão da hipótese de Carlos Gentile de Mello. Cad Saude Publica 1997; 13(2):221-226.

9. Rocha JSY, Ortiz PC, Fung YT. A incidência de cesáreas e a remuneração da assistência ao parto. Cad Saude Publica 1985; 1(4):457-466.

10. Brasil. Ministério da Saúde (MS). Portaria MS/GM $n^{\circ} 2816$ de 29 de maio de 1998. Determina que, no programa de digitação de autorizações de internação hospitalar SISAIH01, seja implantada crítica visando o pagamento de percentual máximo de cesarianas, em relação ao total de partos por hospital. Institui medidas para redução de cesáreas. Diário Oficial da União 1998; 02 jun.

11. Brasil. Ministério da Saúde (MS). Portaria MS/GM $n^{\circ} 865$ de 3 de junho de 1999. Redefini os limites de percentuais máximos de cesarianas que trata o item 01 da Portaria GM/MS/N² 2.816 , de 29 de maio de 1998. Diário Oficial da União 1999; 7 jul.

12. Brasil. Ministério da Saúde (MS). Portaria MS/GM no 2815 de 29 de maio 1998. Inclui, na Tabela de Informações Hospitalares do SUS, procedimentos de atenção ao parto normal sem distócia realizado por enfermeiro obstetra. Diário Oficial da União 1998; 2 jun.

13. Brasil. Ministério da Saúde (MS). Portaria MS/GM no 985 de 05 de agosto de 1999. Cria o Centro de Parto Normal CPN no âmbito do Sistema Único de Saúde. Diário Oficial da União 1999; 26 ago.

14. Diniz CSG. Humanização da assistência ao parto no Brasil: os muitos sentidos de um movimento. Cien Saude Colet 2005; 10(3):627-637.

15. Cecatti JG, Pires HMB, Goldenberg P. Cesárea no Brasil: um direito de opção? In: Galvão L, Díaz J, organizadores. Saúde sexual e reprodutiva no Brasil. São Paulo: Hucitec; 1999. p. 237-258. 
16. Furet F. História "Eventual" e História Serial. In: Silva MBN, organizadora. Teoria de História. São Paulo: Cultrix; 1976. p. 61-65.

17. Chaunu P. Os novos domínios da história serial. In: Silva MBN, organizadora. Teoria de História. São Paulo: Cultrix; 1976. p. 66-72.

18. Rezende J. Obstetrícia. 3a Edição. Rio de Janeiro: Guanabara Koogan; 1974.

19. Rezende J, Montenegro CA. Obstetrícia fundamental. 4a Edição. Rio de Janeiro: Guanabara Koogan; 1984.

20. Rezende J. Obstetrícia fundamental. 6a Edição. Rio de Janeiro: Guanabara Koogan; 1992.

21. Rocha JSY, Simões BJG, Guedes LM. Assistência hospitalar como indicador da desigualdade social. Rev Saude Publica 1997; 31(5):479-487.

22. Dias MAB, Domingues RMSM. Desafios na implantação de uma política de humanização da assistência hospitalar ao parto. Cien Saude Colet 2005; 10(3):669-705.

23. Schreiner M, Costa JSD, Olinto MTA, Meneghel SN. Assistência ao parto em São Leopoldo (RS): um estudo de base populacional. Cien Saude Colet 2010; 15(Supl. 1):1411-1416.

24. Radis Comunicação e Saúde. Rede privada: gestão é determinante. Radis 2012; (117):12-13.

25. Meller FO, Schaffer AA. Fatores associados ao tipo de parto em mulheres brasileiras: PNDS 2006. Cien Saude Colet 2011; 16(9):3829-3835.

26. Juiz de Fora. Secretaria Municipal de Saúde. Relatório do Sistema de Informação Sobre os Nascidos Vivos - 2011. Juiz de Fora: Subsecretaria de Vigilância em Saúde, Departamento de Vigilância Epidemiológica e Ambiental; 2011.

27. Deslandes SF. A ótica de gestores sobre a humanização da assistência nas maternidades municipais do Rio de Janeiro. Cien Saude Colet 2005; 10(3):615626.

28. Brasil. Ministério da Saúde (MS). Diretrizes gerais e operacionais da Rede Cegonha. [acessado 2012 jun. 21] Disponível em: http://portal.saude.gov.br/portal/ saude/gestor/visualizar_texto.cfm?idtxt $=37082$.

29. Tanaka ACd'A, Alvarenga AT. Tecnologia e medicalização na concepção e anticoncepção. In: Galvão L, Díaz J, organizadores. Saúde sexual e reprodutiva no Brasil. São Paulo: Hucitec; 1999. p.198-208.

Artigo apresentado em 16/11/2012

Aprovado em 21/02/2013

Versão final apresentada em 28/02/2013 